\title{
Placental Microbiome and Its Association With Preterm Labor: Systematic Literature Review
}

\author{
Bhuchitra Singh ${ }^{1}$ and Ping Xia ${ }^{2 *}$ \\ ${ }^{1}$ Department of Gynecology \& Obstetrics, Johns Hopkins School of Medicine, USA \\ ${ }^{2}$ Department of Gynecology \& Obstetrics, Johns Hopkins School of Medicine, USA \\ *Corresponding author: Ping Xia, Department of Gynecology \& Obstetrics, Johns Hopkins School of Medicine, USA
}

\begin{tabular}{|c|c|}
\hline ARTICLE INFO & ABSTRACT \\
\hline Received: 幽 April 09, 2019 & \multirow{4}{*}{$\begin{array}{l}\text { Preterm birth is a major cause of mortality and morbidity in infants, and it is also } \\
\text { associated with lifelong health consequences. To understand the etiology of preterm } \\
\text { labor, recent studies have looked into how the placental microbiome differs between } \\
\text { term and preterm births, and how the microbiome affects pregnancy outcomes. This } \\
\text { review synthesized selected studies ( } \mathrm{n}=5 \text { ) from PubMed. Overall, these studies associated } \\
\text { preterm labor with placental bacteria. The research indicates that the placental } \\
\text { microbiome is similar to the human oral microbiome. Studies also show that there are } \\
\text { bacteria present in both term and preterm fetal membranes. Although bacteria exists in } \\
\text { both types, the microbes of preterm membranes are greater in prevalence and species } \\
\text { diversity. In addition, compared to term births, preterm births contained more microbial } \\
\text { DNA in placentas of subjects with chorioamnionitis and without chorioamnionitis. These } \\
\text { findings indicate a positive relationship between bacterial presence, microbial DNA } \\
\text { variety, and preterm labor regardless of bacterial infection status. The reviewed articles } \\
\text { also lead to questions of proper sampling methods and contamination, which will be } \\
\text { discussed using the results of Salter et al. Further research is needed to improve collection } \\
\text { and culture techniques, to ascertain if the placental bacteria are viable, and to find the } \\
\text { functions and mechanisms of entry of the bacteria. }\end{array}$} \\
\hline Published: April 18, 2019 & \\
\hline $\begin{array}{l}\text { Citation: Bhuchitra Singh, Ping Xia. } \\
\text { Placental Microbiome and Its As- } \\
\text { sociation With Preterm Labor: Sys- } \\
\text { tematic Literature Review. Biomed } \\
\text { J Sci \& Tech Res 17(2)-2019. BJSTR. } \\
\text { MS.ID.002962. }\end{array}$ & \\
\hline $\begin{array}{l}\text { Keywords: Microbiome; Placenta; } \\
\text { Placental Microbiome; Preterm Birth; } \\
\text { Pregnancy Outcomes }\end{array}$ & \\
\hline
\end{tabular}

\section{Introduction}

Preterm labor is the presence of contractions of sufficient strength and frequency to effect progressive effacement and dilatation of the cervix less than thirty-seven weeks into gestation. Approximately one in ten children is born preterm. Around fifteen million babies are born preterm annually. The disorders and complications related to prematurity and low birth weight are the leading causes of neonatal death within twenty-eight days of birth [1,2]. This causes more than $50 \%$ of perinatal morbidity and mortality, as well as incurs long-term physical, psychological and economic cost $[3,4]$. According to National Institite of Health in United States $(\mathrm{NIH})$, the preterm birth has risen by $29 \%$ since 1981, with African-American women having the highest incidence. Babies born prior to thirty-four weeks experience the greatest morbidity and mortality [5]. The major risks of preterm delivery to the newborn are respiratory distress syndrome, necrotizing enterocolitis, jaundice, hypothermia, hypoglycemia, increased incidence of infections, retinopathy of prematurity, and death [6,7]. Moreover, preterm birth results in mental retardation (one in five children), vision impairment (one in three children), and cerebral palsy at rate of 50 percent of the pretern children born $[5,8]$. It also has long-term complications for the baby such as higher risk of cardiovascular diseases, diabetes, and a possible higher risk of cancer [9].

Such high risks draw great attention by the NIH. Its prevention and etiology become far more important. The NIH has identified a number of risk factors which were categorized $[5,10]$. In addition, there is a complex set of pathogenic pathways that precipitate preterm labor. The primary route of infection that leads to preterm delivery derives from bacteria ascending from the genital tract. These include bacterial vaginosis, Group B Streptococcus, Chlamydia and Mycoplasmas [11,12]. Infections can also be transplacental (blood-borne), transfallopian (intraperitoneal) and iatrogenic (via invasive procedures). Effective intervention against preterm birth is to the source of an etiology. Extensive studies have shown the association of placenta with perinatal outcomes, including preterm birth [13]. This organ plays an important role in fetal growth and metabolism [14]. The chorionic villi, forming the placental membrane, are the main functional site where exchange between maternal and fetal blood occurs. The villi also facilitate the transfer of gasses, nutrients, and provide the endocrine, enzymatic, 
and immunological functions. Such a range of functions mean that the placental microbiome could determine the timing of the birth.

A microbiome is a collection of genetic material derived from microbiota that inhabit from an environment. It is a dynamic ecosystem. A microbiome typically comprises communities of symbiotic, commensal and pathogenic bacteria (along with fungi and viruses) [15]. The majority of microbiota living in and on us are not invaders, but rather beneficial colonizers $[14,16]$. The prevailing theory is that the human microbiome is seeded at birth and becomes more robust over life [6,7]. However, recent evidence from highthroughput metagenomics studies have demonstrated evidence of bacterial DNA in the intrauterine environment, including the placenta, and in the meconium of newborns, suggesting an in-utero exchange of bacteria. The central dogma in reproductive medicine has been that the placenta is sterile in utero, except for times of infections that lead to spontaneous preterm birth [13,17]. However, recent discovery of bacterial DNA on the placenta suggests this is untrue even in normal, healthy pregnancies [4]. This review aims to conduct a comprehensive literature synthesis of new information on the placental microbiome in preterm and term births.

\section{Methods}

The reviewed articles were found after conducting a literature search in PubMed. Key terms in the search were "Placental Microbiome," "Maternal Placental Microbiome," "Preterm Birth," "Preterm Labor," and "Pregnancy Outcomes." In addition, criteria for selection included studies on human subjects, and research published in peer-reviewed journals between January 2000-March 2018. Through the initial search, twenty-one articles were identified either from these parameters or from reference lists. The articles were excluded if they were reviews, if they did not study the association between preterm birth and the placental microbiome, or if they focused on immune system effects. After applying the exclusion criteria, five articles remained for review is a flowchart that outlines how studies were selected.

\section{Results}

The literature reviews are summarized below Stout et al. [5] conducted a cross-sectional study included 195 patients. Of these, 68 had preterm deliveries and 127 were term deliveries. According to the authors it was the "first morphological documentation of intracellular organisms in the deciduous basal plate of human placenta". The placentas were collected within 12 hours from the time of delivery. The samples were from a superficial area of the basal plate of the placenta. These samples were fixed in formalin, then embedded in paraffin. The bacterial species were identified using histological staining, which was considered as a different technique, cited by Salter et al. [18]. The advantage was that researchers could determine the morphology and location of the bacteria within the basal plate cells. Their results showed that $27 \%$ of the specimens had evidence of intracellular bacteria that was similar to the bacteria in the tissues collected from both term and preterm tissues with no statistical significance $(\mathrm{p}=0.7)$. There was also an increase of bacteria in the basal plate for births before 28 weeks compared to the term births. The authors suggested that future research could look into identifying the functions and origins of the intracellular bacteria. A limitation of the Stout's study was that it was an observational study, therefore causality is difficult to determine.

Another cross-sectional study with 6 cohorts included a total of 71 women Prince et al. [15] Of these, 27 had term deliveries and 44 had preterm deliveries. The objective of this study was to assess the placental microbiome from preterm births, comparing between the specimens with or without chorioamnionitis. The whole placenta was collected immediately after delivery in sterile bags and kept in a refrigerator until sampling. The samples were collected using swabs of the chorion and villous placental membranes on the fetus side and were sent for bacterial cultures and whole-genome sequencing. In addition to the placenta specimens, cord blood was also collected and analyzed from the participants. This study demonstrated that there were more bacterial DNAs in the placentas from preterms births compared with term births, regardless of chorioamnionitis status. Ureaplasma, Fusobacterium and Streptococcus species were found in the preterm placentas. In contrast, term specimens exhibited the presence of Enterobacter and Lactobacillus species. The critical limitations of this study were that the authors could not distinguish the classes of antibiotics used for the patient's treatments. The whole-genome sequencing added more complexity to the study outcomes because of potential contaminations in the DNA extraction kits, as commented by Salter et al. [18]. The third cross-sectional study recruited 74 women Jones et al. [19]. There were 21 term deliveries and 53 preterm deliveries with the preterm births categorized into PPROM (prolonged rupture of membranes), Preterm Labor (PTL) with intact membranes (spontaneous preterm labor) and indicated preterm delivery. The placentas were collected into a sterile container immediately after delivery. The samples from five sections including amnion, chorion, the center next to the umbilical cord, and the sample from periphery of the placenta. Broad-range 16S rDNA PCR was used to identify the bacterial species.

Their results showed that microbes were found in both preterm and term fetal membranes. There were greater amounts and variations in the bacterial species found in the preterm tissues. In the PTL group, over $60 \%$ showed two or more bacterial species whereas only $20 \%$ of the term group had two or more species. The most common species identified from preterm tissues was Ureaplasma parvum. In addition, there was a strong association between histological chorioamnionitis and increased maternal immune paresis. To further confirm the findings, the blood samples were collected from women in preterm labor or prior to preterm caesarean section.

Expression of Major Histocompatibility Complex (MHC) Class II via flow cytometry. MHC Class II molecules are important in cells that initiate immune response. In women with positive presence of bacteria, there was a significant decrease in the expression of MHC Class II. However, based on the findings of Salter et al. [18], the technique of quantitative PCR for bacterial biomass is flawed. These authors performed qPCR of bacterial 16S rRNA and found the presence of background DNA because the copy number remained stable despite of sample dilutions. This contamination is estimated to be about 500 copies per microliter of elution volume 
used the similar technique of $16 \mathrm{~S}$ rDNA PCR confirming that such results were from contamination. Therefore Jones et al. optimized the detection of bacteria of interest by using species-specific real time assays.

Resulted PCR products were further cloned and verified by sequencing. Another small-scaled cross-sectional study Doyle et al. [12] collected placental samples from 24 deliveries that included 14 patients preterm deliveries and 10 term deliveries. The samples from the chorion and amnion. These authors did not specify the conditions and procedures they used to collect samples from the placenta. The preterm tissues were assessed and diagnosed positive for histological chorioamnionitis. Extracted DNA from the tissues were analyzed by using 16S DNA PCR and pyrosequencing techniques. Salter et al. [18] discussed the technique of 16S rDNA PCR about potential contamination but not pyrosequencing.

The results indicated that there were common bacterial genera found in term births regardless of delivery (Caesarean or vaginal). These genera included Streptococcus, Microbacterium, Corynebacterium and Rhodococcus. However, some bacterial genera were found in significant amounts in preterm tissues. This included: Fusobacterium nucleatum, Mycoplasma hominis, Aerococcus christensenii, Streptococcus anginosus, Streptococcus agalactiae and Gardnerella vaginalis. Aagaard et al. [14] conducted a case cohort study. Investigators took 48 placental samples from a cohort of 320 patients. They had extensive medical data of the cohort. There were initially two case-cohort data sets, one with preterm birth samples and the second with subjects who had laboratory evidence of antepartum infections (STDs, UTIs, etc.). The subjects were matched for age, delivery mode, BMI, and race among other factors. The investigators collected the placentas into sterile containers immediately following delivery. Four to six, 1 cubic centimeters of tissue were taken from $4 \mathrm{~cm}$ around the cord insertion site of the placenta. The samples were then sent for DNA analysis using whole-genome shotgun sequencing, and the species compared to other human body sites.

The critical findings of the study were that the placental microbiome was unique but also similar to the oral microbiome. In addition, there was bacteria found in both term and preterm deliveries common species found included Firmicutes, Tenericutes, Proteobacteria, Fusobacteria and Bacteroidetes phyla. One difference is that the preterm specimens included Burkholderia whereas term specimens included Paenibaccilus. Another finding was that the placental samples of women with a history of antepartum infections also contained Streptococcus and Acinetobacter species compared to those without a history. This study used metagenomics techniques like whole-genome shotgun sequencing suggested metagenomics, like PCR, also had a potential of contamination by foreign DNA. These results again called into question if the DNA sequenced from the placental samples actually came from the tissue or from the DNA kit or the environment, especially in the cases where there is low bacterial biomass from the sample. This is a critical limitation of the study.

Other concerns of the study includes how they compared the placental microbiome to reference data from other human body sites (oral, gut, etc.) in non-pregnant participants. The researchers did not have the practical means to sample all these sites themselves, so they used reference data from another source. This calls into question the comparison between non-pregnant participants and the pregnant participants. Another limitation was the low bacterial biomass of the placenta. This relates back to the prior questions raised by Salter et al. [14] were able to overcome this limitation by using a large sample size of primary specimens, and the use of multiple biological replicates.

\section{Discussion}

These five studies provide experimental evidence that bacterial DNA may exist in the placentas of both term and preterm births. In addition, the findings indicate a higher prevalence and a greater variety of bacteria in preterm births. This suggests bacterial invasion of the placenta may result in preterm labor. Other notable outcomes were the differences in the most frequent bacterial families found in preterm samples compared to term samples. Altogether, these studies present a common indication of the presence of a placental microbiome [12,18-20]. The results of the reviewed articles can be put into context with other literature that did not qualify for review but were related to our interests. Rehbinder et al. [21] did not find microbiota in the amniotic fluid of pregnancies until the beginning of labor. Their findings support the idea of sterile womb. This contrasts with implications from this review that challenge the idea. Another study, Lannon et al. [22] found the presence of lactobacilli and fastidious bacteria in the chorioamniotic membrane of term pregnancies, and that not all bacterial colonization was associated with placenta inflammation. Such conclusions support the presence of a placental microbiome and suggest a pathway of colonization bacterial ascension from the lower genital tract to the womb. In another study, Parnell et al. [23] the findings not only supported the presence of a placental microbiome but also found that the microbiota have distinct genomic profiles based on the region of placenta they were obtained. Additionally, earlier reviews debated about the existence of a placental microbiome and the possible connection to preterm labor [24,25].

There are also differences between the reviewed studies. One difference is the method of measuring preterm birth. Stout et al. $[5,14]$ both measured it as births at less than 37 weeks gestational age. However, Jones et al. [19] measured it as less than 32 weeks, similar to Doyle et al. [12] who measured it as between 28-32 weeks. Another major difference was the different methods of measuring bacteria, with some studies using PCR and others using whole-genome shotgun sequencing or histological stains or bacterial cultures. A potential and critical limitation of these studies come from the methods of collecting placental samples. Reagent contamination is a concern. In the studies of Salter et al. [18,26-30], investigators found significant evidence of contaminating bacterial DNA in extraction kits and laboratory reagents. This is especially pronounced in cases of samples with low bacterial biomass to begin with. The results of Salter et al. [18] have implications for the reviewed studies that used PCR based analysis and metagenomics. The concerns raised by Salter et al. [18,31-32] show the importance of adhering to sterile protocol. 
Overall, the reviewed articles put forth an association between the placental microbiome and preterm delivery. However, questions remain if the bacterial DNA identified in these experiments represent a living ecosystem, and whether the bacteria are viable. In addition to these questions, further studies can look into the exact roles and functions of the microbes, and the pathways that these bacteria are introduced into the placenta. In other words, what are the transmission routes of the bacteria? Did they come from other human body sites such as the oral or vaginal microbiomes?

\section{Conclusion}

Based on these studies, the orthodoxy of the sterile womb has been challenged by evidence of bacterial presence in both preterm and term placental specimens. Some findings even suggest that the placental microbiome affects preterm labor. However, concerns of contamination with the sampling methods, and the lack of large, well-designed observational comparative studies reveal gaps in the current state of the field. Other questions are the route of colonization, the functions and viability of the identified bacteria, the percentage of normal pregnancies that have bacteria present in the placenta, and the future improvements in sterile sampling techniques. These findings to date are significant to the field of maternal and infant health, especially the prevention of preterm births.

\section{Acknowledgment}

The authors would like to thank Professor Clement L.K. Chan for the Perpetuity Endowment Fund in supporting infertility research for the Johns Hopkins School of Medicine. The author wishes to extend gratitude towards the Capstone Project Program at the Johns Hopkins Bloomberg School of Public Health and Ms. Carmen Jung for her editing skills and help with this paper.

\section{References}

1. ML Wang, DJ Dorer, MP Fleming, EA Catlin (2004) Clinical outcomes of near-term infants, Pediatrics. 11492): 372-376.

2. (2016) Preterm Birth. World Health Organization.

3. S Petrou (2005) The economic consequences of preterm birth during the first 10 years of life. BJOG 1: 10-15.

4. Collins D (2014) Not Sterile, After All: The Placenta's Microbiome. NIH Director's Blog.

5. MJ Stout, B Conlon, M Landeau, I Lee, C Bower, et al. (2013) Identification of intracellular bacteria in the basal plate of the human placenta in term and preterm gestations. American Journal of Obstetrics and Gynecology 208(3): 226-227

6. X Wu, B He, J Liu, H Feng, Y Ma, et al. (2016) Molecular Insight into Gut Microbiota and Rheumatoid Arthritis. International Journal of Molecular Sciences 17(3): 431.

7. T Halmos, I Suba (2016) Physiological patterns of intestinal microbiota The role of dysbacteriosis in obesity, insulin resistance, diabetes and metabolic syndrome. Orvosi hetilap 157(1): 13-22.

8. I Cho, MJ Blaser (2012) The human microbiome: at the interface of health and disease. Nature Reviews Genetics 13(4): 260-270.

9. JJ Faith, JF Colombel, JI Gordon (2015) Identifying strains that contribute to complex diseases through the study of microbial inheritance. Proceedings of the National Academy of Sciences. 112(3): 633-640.

10. Jane Norman (2005) Preterm labor: Managing Risk in Clinical practice, Cambridge University Press, UK.
11. (2016) Preterm Birth, CDC.

12. RM Doyle, DG Alber, HE Jones, K Harris, F Fitzgerald, et al. (2014) Term and preterm labour are associated with distinct microbial community structures in placental membranes which are independent of mode of delivery. Placenta 35(12): 1099-1100.

13. TM Wassenaar, P Panigrahi (2014) Is a foetus developing in a sterile environment? Letters in applied microbiology 59(6): 572-579.

14. Aagaard K, Ma J, Antony KM, Ganu R, Petrosino J, et al. (2014) The placenta harbors a unique microbiome. Science Translational Medicine 6(237): 65.

15. AL Prince, J Ma, PS Kannan, M Alvarez, T Gisslen, et al. (2016) The placental microbiome is altered among subjects with spontaneous preterm birth with and without chorioamnionitis. American Journal of Obstetrics and Gynecology 214(5): 24.

16. TA Meulen, HJ Harmsen, H Bootsma, FK Spijkervet, FG Kroese, et al. (2016) The microbiome systemic diseases connection. Oral diseases 22(8): 719-734

17. (2014) The Integrative HMP (iHMP) Research Network Consortium. The Integrative Human Microbiome Project (iHMP): Dynamic Analysis of Microbiome-Host Omics Profiles During Periods of Human Health and Disease. Cell Host \& Microbe 16(3): 276-289.

18. SJ Salter, MJ Cox, EM Turek, ST Calus, WO Cookson, et al. (2014) Reagent and laboratory contamination can critically impact sequence-based microbiome analyses. BMC Biology 12: 87.

19. Jones HE, Harris KA, Azizia M, Bank L, Carpenter B, et al. (2009) Differing prevalence and diversity of bacterial species in fetal membranes from very preterm and term labor. Plos one 4(12): 8250.

20. (2016) The Human Microbiome, Learn genetics.

21. EM Rehbinder, KC Lødrup Carlsen, AC Staff, IL Angell, L Landrø L, et al. (2018) Is amniotic fluid of women with uncomplicated term pregnancies free of bacteria? American Journal of Obstetrics and Gynecology 219(3): 289.

22. SMR Lannon, KM Adams Waldorf, T Fiedler, RP Kapur RP, K Agnew, et al. (2018) Parallel detection of lactobacillus and bacterial vaginosisassociated bacterial DNA in the chorioamnion and vagina of pregnant women at term. The Journal of Maternal-Fetal and Neonatal Medicine 12: $1-9$.

23. LA Parnell, CM Briggs, C Bin, O Delannoy Bruno, AE Schreiffer, et al. (2017) Microbial communities in placentas from term normal pregnancy exhibit spatially variable profiles. Scientific Reports 7: 11200.

24. IU Mysorekar, B Cao (2014) Microbiome in parturition and preterm birth. Seminars in Reproductive Medicine 32(1): 50-55.

25. ML Power, C Quaglieri, J Schulkin (2017) Reproductive Microbiomes: A New Thread in the Microbial Network. Reproductive Sciences 24(11): 1482-1492.

26. JD Boyd, WJ Hamilton (1970) The Human Placenta. W Heffer \& Sons Ltd. Collins D, Cambridge, UK.

27. K Bernischke (2012) The pathology of Human Placenta. Springer Science \& Business Media, New York.

28. BM Carlson (2013) Human Embryology and Developmental Biology, ( $5^{\text {th }}$ edn.). CV Mosby Co, New York.

29. SR Gill, M Pop, RT Deboy, PB Eckburg, PJ Turnbaugh (2006) Metagenomics analysis of the human distal gut microbiome. Science 312(5778): 13551359.

30. CM Salafia, JC Pezzullo, J López Zeno, S Simmens, VK Minior, et al. (1995) Placental pathologic features of preterm preeclampsia. American Journal of Obstetrics and Gynecology 173(4): 1097-105.

31. NM Gude, CT Roberts, B Kalionis, RG King (2004) Growth and function of the normal human placenta. Thrombosis research 114(5): 397-407.

32. A Lauder, A Roche, S Sherrill Mix, A Bailey, A Laughlin, et al. (2016) Comparison of placenta samples with contamination controls does not provide evidence for a distinct placenta microbiota. Microbiome 4: 29. 


\section{ISSN: 2574-1241}

DOI: 10.26717/BJSTR.2019.17.002962

Ping Xia. Biomed J Sci \& Tech Res

(C) $(9)$ This work is licensed under Creative

Submission Link: https://biomedres.us/submit-manuscript.php

$\begin{array}{ll}\text { BIOMEDICAL } & \text { Assets of Publishing with us } \\ \text { RESEARCHES } & \text { - Global archiving of articles } \\ \text { - Immediate, unrestricted online access } \\ \text { - Rigorous Peer Review Process }\end{array}$

